Relmecs, diciembre 2017, vol. 7, no. 2, e028, ISSN 1853-7863

Universidad Nacional de La Plata. Facultad de Humanidades y Ciencias de la Educación.

Centro Interdisciplinario de Metodología de las Ciencias Sociales.

Red Latinoamericana de Metodología de las Ciencias Sociales

\title{
Construyendo una noción de campesinos con un método 1
}

\author{
Building a notion of peasants with a method
}

\author{
Mónica Cecilia Moreno Moreno * \\ * Universidad Nacional de Colombia, Colombia | mocamorenomo@gmail.com
}

\section{PALABRAS CLAVE RESUMEN}

Metodología

Sociología

\section{KEYWORDS}

Methodology

Sociology
El objetivo del artículo es mostrar la forma en que el sociólogo Orlando Fals Borda construyó una noción que resaltaba la creatividad y apertura al cambio de los campesinos colombianos. Se argumenta que esta idea fue construida gracias a la implementación que Fals hizo del método de experimentación por participación. Se analiza este método seleccionando categorías presentes en las notas de campo elaboradas por Fals y se muestra su relación con procesos de cohesión comunitaria y con un plan para extender a nivel nacional la modernización rural. 


\section{Introducción}

Que los campesinos colombianos no eran pasivos y conservadores por naturaleza y, por el contrario, podían tener actitudes muy abiertas a los cambios y ser muy creativos, fue una de las principales conclusiones a las que llegó en sus primeros años de trabajo en terreno Orlando Fals Borda, uno de los pioneros y representantes más destacados de la investigación sobre sociología rural que incluía trabajo de campo en Colombia y Latinoamérica (Smith, 1960). Al plantear esta noción de campesinado placontrovertía la idea de la melancolía o herencia indígena ligada a un supuesto conservadurismo campesino inexorable, idea defendida por ensayistas colombianos que precedieron inmediatamente la labor sociológica inicial de Fals (Fals, 1956a López de Mesa, 1930; Hernández, 1936; Solano, 1953; Triana, 1951). Con su idea sobre el campesinado implícitamente criticaba también la ausencia del campesino, principalmente del pequeño cultivador, en la implementación de políticas y legislaciones previas a los años cincuenta (esto es, en la ley 200 de 1936 y en la ley 100 de 1944), y la condición de pobreza generada por esta omisión (Machado, 2009). Según el propio Fals, la concepción que planteaba cuestionaba el prejuicio de la sociedad a la que pertenecía acerca de la pasividad campesina, procurando romper el abismo que separaba al agricultor del "grupo educado". Miembros de la élite y sus colegas deberían enterarse de la capacidad del campesinado para cambiar sus prácticas y herramientas agrícolas (Fals, 1961).

La defensa de la idea de campesinos que podrían superar su pasividad y la tendencia a estar aferrados a su tradición estaba condicionada a una intervención externa adecuada que denominaba estímulo. Su noción era además funcional a la convicción acerca de la necesidad de elevar el nivel de vida del campesinado nacional, tan atada al miedo a la sublevación social y a la idea de la ciencia como institución neutral que, inmerso en la modernización de la segunda posguerra, defendía Fals. Esto en tanto la aceptación de los campesinos de las innovaciones era un requisito sin el cual esta ideología modernizante no funcionaría.

¿Qué motivó esta tesis de Fals? En otras palabras, ¿de qué forma pudo constatar que la idea del campesinado colombiano como aquel carente de capacidad innovadora era un mito? Esta es la principal pregunta que con este texto busco responder. Planteo que, mediante su aplicación del método “experimentación por participación”, Fals desmintió esa idea.

La importancia de resaltar la forma en que a través de una metodología Fals construyó una noción de campesinado, obedece en buena medida a que se trata de una condición que permitió la llegada de su transformación académico-política. El que Fals ya desde los años cincuenta empezara a concebir al campesino como capaz de cambiar, permitió que a comienzos de los setenta creara una perspectiva más amplia que esta noción, en la que sería "el pueblo" mismo el que podría participar en la investigación con el fin de transformar su realidad.

Algunos estudiosos de Fals se han aproximado a este tema. Jaramillo encontró, entre los elementos de continuidad de su trayectoria, su consideración acerca de la inteligencia de los campesinos, central en el argumento que quiero presentar. Sin embargo, preguntas distintas a la del origen de esta tesis planteada por Fals motivaron sus análisis (Jaramillo, 1996). Tanto Jaramillo como Rojas han situado el enfoque de Fals, orientado a la difusión de innovaciones de los años cincuenta, como un rasgo apenas normal, comprensible, de sus primeros acercamientos al terreno y de sus etnografías iniciales, teniendo en cuenta el momento histórico de la sociología y en general los procesos de modernización rural promovidos académica y políticamente en estos años (Rojas, 2014a). Pero esto último también es distinto al contenido de este capítulo. Recientemente, William Sánchez incluyó un análisis de la participación de Fals en los programas de extensión rural en Colombia a partir de la apropiación social de la ciencia y la tecnología, y con base en las publicaciones de este último en la revista agricultura tropical. Algunos elementos señalados por Sánchez están incluidos de una manera considerablemente más profunda en este trabajo (Sánchez, 2014b). 


\section{Metodología}

El argumento y el texto que presento se basan principalmente en la revisión de notas de campo y material ubicado en carpetas sobre agricultura y nivel de vida del Archivo Satélite de Ciencias Humanas de la Universidad Nacional en Bogotá (ASCH/B), y del Archivo Orlando Fals Borda del Archivo de Investigadores ubicado en el Archivo Histórico de la Universidad Nacional de Colombia de Bogotá (en adelante AHUNC/B). Además, el capítulo se basa en los apartados sobre agricultura y nivel de vida de las tesis de maestría y doctorado de Fals, artículos que escribió durante los años cincuenta e inicios de los años sesenta, como así también entrevistas a campesinos y campesinas de la vereda Saucío, que conocieron el trabajo que Fals adelantó en dicho lugar.

En buena medida, este capítulo se inspira en Guber y sus planteamientos para la comprensión del conocimiento etnográfico (2011). Su análisis del trabajo de campo de Esther Hermitte sugiere tomar al investigador y sus prácticas como parte del objeto de estudio, además de desentrañar los rasgos de las metodologías y estrategias empleadas en terreno, identificando actividades específicas desarrolladas por el investigador. Guber permite interrogarse sobre aquello en que consistían las estrategias y herramientas metodológicas de Fals en los años cincuenta. Especialmente la pregunta ¿de qué se trataban los experimentos que promovía en Saucío? es un asunto transversal en este texto, lo que me llevó a identificar una relación estrecha entre dichos experimentos y el cuestionamiento que Fals hizo sobre la idea del campesinado colombiano como uno adormecido y estrictamente tradicionalista.

En este ejercicio es útil también el análisis de Shapin y Schaffer acerca de las que denominaron tecnologías, utilizadas por Boyle con el fin de construir hechos experimentales sobre neumática y producir las condiciones para movilizar consenso sobre ellos. Llamaron tecnología material a la relacionada con la justificación que Boyle hacía de crear y usar la bomba de aire teniendo en cuenta que su uso no se había expandido; hablaron de tecnología social refiriéndose a las convenciones que debían emplear en sus reportes mutuos quienes experimentaban, y a la forma en que reivindicaban sus conocimientos; denominaron tecnología literaria a aquella que tenía que ver con la comunicación de los fenómenos experimentados a quienes no habían sido testigos directos de los experimentos, y con la forma en que debía escribirse sobre estos últimos. Shapin y Schaffer mostraban la manera en que esta última tipología de Boyle ilustraba las relaciones sociales de la comunidad de filósofos experimentales, como así también la forma en que se creaban fronteras lingüísticas de la comunidad de experimentadores. Su estudio es útil para tratar de entender lógicas en las notas de campo de Fals y algunos materiales de archivo relacionados con los experimentos que promovió (2005).

\section{Resultados y discusión}

Estructura y contenido de las notas de campo de Fals

Una muy buena parte de los apuntes de Fals sobre Saucío, la vereda andina colombiana donde investigó y promovió experimentos en los años cincuenta, ubicados en las carpetas denominadas agricultura, nivel de vida y

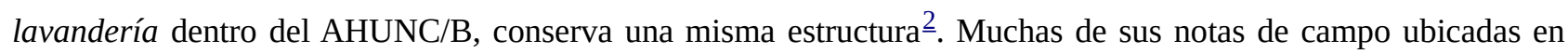
estas carpetas tienen, arriba a la derecha, una o varias categorías cuyo uso repite y a las cuales antecede un corchete: difusión, innovación, contacto cultural, demostración, mecanización, resistencias, aceptación, introducción, son algunas de los más frecuentemente utilizadas. A la izquierda arriba, muchas de sus notas tienen un título general que para los casos revisados corresponden a Agricultura y Nivel de vida, más uno que da cuenta de la especificidad de esas áreas sobre la cuales trataría en cada nota. Ejemplos de este último tipo de título son abonos papa, recolección en zurrones cambia a canastos o desinfección de semilla, para el caso de la carpeta Agricultura, y cocina, plancha de gasolina o pozo de agua que se encuentran en la carpeta Nivel de vida.

En ocasiones estos elementos no están ubicados exactamente en los lugares que describí, o están entremezclados, conservando siempre su ubicación en el encabezado de las notas de campo. Estas categorías y títulos están acompañados por la fecha y, obviamente, por el contenido de los apuntes. 
Pero ¿cuál era el contenido de estas notas? y ¿podrían la estructura y el contenido de las mismas sugerir pistas que permitieran rastrear orientaciones teóricas y metodológicas de Fals? Al revisar el interior de las carpetas agricultura y nivel de vida, se observa que muy buena parte de las notas de campo y la estructura presentada corresponde a experimentos coordinados por Fals en Saucío para promover el aumento de la productividad agrícola, y además lo que él denominaba elevación del nivel de vida de esta vereda.

Estos dos últimos asuntos íntimamente relacionados, productividad y nivel de vida, eran parte importante de los análisis que hacía Fals al final de su trabajo de terreno en Saucío. En "Campesinos de los andes: estudio sociológico de Saucío”, su primera etnografía y quizá la más reconocida entre las que elaboró en los cincuenta, identificaba el primero de estos problemas al detallar los utensilios agrícolas empleados por los agricultores saucitas, y al detectar un elevado número de pequeños propietarios que había resultado en buena medida de un proceso de subdivisión de la tierra que inició con la parcelación del resguardo de indígenas que había en ese lugar siglos atrás. Hay que aclarar que pese al reconocimiento que Fals hacía de su enorme importancia, la necesidad de aumentar la producción agrícola no era el único ni más importante límite que para Fals había en Saucío. La concentración de la tierra que demandaba la negociación con propietarios ausentes, incluidos los dueños de "Las Julias”, hacienda de la vereda, tenía más centralidad para él respecto a la agricultura y el mejoramiento del nivel de vida en Saucío (Fals, 1961, p. 89 y pp. 98-99.).

Aunque su consideración acerca de la importancia de modernizar los utensilios agrícolas y rurales en Saucío aparece inicialmente con la publicación de su tesis de maestría, desde sus primeros años en terreno había identificado esta problemática, procurando hacerla evidente para algunos saucitas e intentado convencerlos acerca de la importancia de introducir métodos y herramientas modernas.

La promoción de experimentos fue una actividad que Fals desarrollo tempranamente en sus años en terreno. Fue, sin embargo, entre 1956 y 1959 cuando parece haberlo hecho con mayor intensidad al adelantar actividades investigativas y de experimentación, no solo en Saucío, sino en lugares aledaños como municipios del vecino departamento de Boyacá como trabajador del Servicio Técnico Colombiano-Americano (STACA), el Instituto de Investigaciones Tecnológicas de la Caja Agraria, el Centro Interamericano de Vivienda y Planeamiento Urbano (CINVA) y la Organización para la Alimentación y la Agricultura (FAO)

El modelo institucional de cambio tecnológico

Desde los años cuarenta del pasado siglo, el aumento de la industrialización, la urbanización y el crecimiento poblacional experimentados en países como México, Colombia, Perú y Ecuador empezaban a generar preocupaciones por el crecimiento de la demanda de productos agrícolas que implicaban. Ante esta situación los Estados formalizaron progresivamente actividades relacionadas con tecnología agrícola que cobraban una importancia considerable a nivel global. Que la tecnología agrícola permitiría disminuir los costos de producción, como así también aumentar el nivel de vida de la población rural, era un punto de partida fundamental del modelo institucional de cambio tecnológico (Trigo, Piñeiro y Sábato, 1983, p. 109).

Generar y transferir tecnología agropecuaria en América del Sur eran así tareas centrales en este tipo de perspectiva que guió la creación y el accionar de institutos de investigación agraria con la participación y el apoyo del Estado. De ese modo se buscaba emular el "Experimental Station System" estadounidense, en el que las estaciones eran los lugares por excelencia donde se ejecutaban experimentos con productos e insumos agrícolas, y donde se trabajaba en conexión con prácticas agrícolas en el campo y con trabajos intelectuales de facultades de agronomía y sociología rural (Fitzgerald, 1994). 
La adopción de dicho modelo surgió como consecuencia de dos concepciones acerca de la tecnología agrícola en relación con Latinoamérica: 1) aquella según la cual la incorporación de tecnología es un elemento fundamental para el desarrollo agropecuario, y 2) una para la que una amplia variedad de tecnologías existentes y disponibles a nivel internacional eran potencialmente utilizables por el sector productor de Latinoamérica, que veía en el aseguramiento de la transferencia de conocimientos de países desarrollados a países subdesarrollados el problema fundamental (Trigo et al., 1983, pp. 101-102).

La implementación del modelo institucional para el cambio tecnológico de finales de los cincuenta en Latinoamérica se caracterizó por tener apoyo externo técnico y financiero. Este apoyo convergía con la política externa de Estados Unidos implementada a partir de 1951 (Punto IV), y se materializó con la creación de nuevos institutos como el Instituto Nacional de Tecnología Agropecuaria (INTA) en Argentina, el Instituto Nacional de Investigación Agropecuaria (INIAP) en Ecuador y el Instituto de Investigaciones Tecnológicas (IIT) en Colombia (Trigo et al., 1983, p. 102) ${ }^{\underline{3}}$.

La idea sobre la necesidad de la difusión de tecnología agrícola en Latinoamérica era compartida por la Comisión Económica para América Latina (CEPAL), organismo que abogaba por la planificación y la modernización estatales y defendía la racionalización de los recursos con que se contaba en la región. Tal apuesta hacía parte de la política de fomento a la sustitución de importaciones mediante la industrialización promovida por esa misma institución; esto con base en un diagnóstico que daba cuenta del deterioro histórico de los términos de intercambio entre el centro y la periferia, deterioro que era fruto de la concentración del progreso técnico en el centro (Dagnino, 1979, pp. 15-16; Trigo et al., 1983, p. 116; Escobar, 1996, pp. 160-161). Promover la adaptación y difusión de tecnología agropecuaria "en estrecho contacto con los productores” era una característica adicional de ese modelo adoptado desde la segunda mitad de los cincuentas en Latinoamérica (Trigo et al., 1983, p. 111).

Habiendo presentado este marco ideológico y político, daré cuenta de los experimentos de Fals concentrándome en algunas categorías presentes en sus notas de campo: resistencias, adaptaciones, demostraciones y difusión.

\section{Resistencias}

En su interés por poner en marcha experimentos, Fals prestaba una especial atención a la forma en que se daban los procesos de difusiónde herramientas y prácticas agrícolas, o de artefactos e ideas relacionados con el nivel de vida en Saucío. Esta preocupación estaba íntimamente ligada al problema de la resistencia frente a la modernización veredal. Fals se preguntaba ¿quién o quiénes habían actuado como fuentes de difusión de determinada práctica o artefacto?, procurando así identificar resistencias a la modernización.

La difusión de una idea, práctica o artefacto moderno, que Fals buscaba con su investigación y sus experimentos en los años cincuenta e inicios de los sesenta, no era un procedimiento sencillo. Pensar en la difusión estaba directamente relacionado con las "resistencias" o razones por las cuales la pretendida introducción de cierto instrumento o práctica era rechazada o medianamente aceptada. La identificación de estas resistencias o razones era, desde el inicio hasta el final de cada uno de los experimentos coordinados por Fals, fundamental.

Una razón por la cual las resistencias eran un elemento apenas normal de los experimentos de Fals tiene que ver con el carácter externo de sus propuestas. Tenía la certeza de que sus propuestas al ser externas a la comunidad no necesariamente encajaban en la misma. Es decir, consideraba que sus iniciativas eran estandarizadas, por lo cual debían sufrir procesos de adaptación.

La identificación de las resistencias era la base sobre la cuál Fals buscaba formas efectivas para convencer a los campesinos acerca de la importancia de dejar atrás sus formas tradicionales de trabajar la tierra o vivir en su vereda. De ahí la importancia que tenía en sus experimentos el prestar una atención muy minuciosa a aquello que explicaba las resistencias.

La negativa parcial o total de los saucitas frente a las iniciativas de Fals era entonces parte esencial de las consideraciones de este último en su promoción del cambio en Saucío, tal como lo era para otros cientistas 
sociales interesados en promover la modernización rural en esos años $\stackrel{4}{4}$. Las resistencias de los saucitas eran para Fals respuestas apenas naturales y esperadas. Por consiguiente, tenía claro que el éxito de los experimentos, o la efectiva introducción de determinado artefacto o práctica modernos, no necesariamente se daban, y en caso de alcanzarse no se obtenían automáticamente.

En otras palabras, nada extraordinario había en que propuestas de cambio que Fals planteaba fueran descartadas por los campesinos, o que la confianza que se despertara en ellos no fuera inmediata. Esta noción coincide con la idea que Wynne sugirió para referirse a la relación entre campesinos y expertos, partiendo del caso de los habitantes de la región de Inglaterra que fue afectada por las explosiones en la planta de Chernóbil: la confianza de los locales en los expertos no es un proceso automático(2004). Para Fals era claro que sólo al encontrar argumentos suficientemente convincentes los campesinos aceptarían introducir sus propuestas.

En la lectura de Fals no siempre los campesinos se negaban a implementar una práctica o herramienta moderna por su apego a la tradición. A veces lo hacían por razones lógicas, bien fueran de tipo técnico o económico. Tal forma de comprender las resistencias da cuenta de una noción de los campesinos como inteligentes, con capacidad analítica, y abiertos al cambio siempre y cuando existieran razones suficientemente justificadas para introducir prácticas y herramientas nuevas. Esto puede verse explícitamente en la síntesis y propuesta de tipo conceptual en referencia a lo que denominó en 1959 marco de referencia teórico para el cambio social, y que publicó en una serie de monografías financiadas por la Fundación Ford a la Facultad de Sociología de la Universidad Nacional liderada por Fals desde 1959 (2010b). La atención de Fals a razones técnicas y económicas como fuente de resistencia a sus iniciativas aparece, además, implícitamente en las notas de campo que tomó durante los cincuenta, y explícitamente como mostraré.

$\mathrm{Al}$ revisar las notas de campo en los años cincuenta de Fals que se basaron en sus investigaciones y experimentos en Saucio, pueden encontrarse repetidas situaciones en las que campesinos rechazaron innovaciones basados en argumentos de tipo económico o técnico ${ }^{5}$. Es el caso de la "resistencia” de don Francisco a la idea propuesta por Fals de utilizar cajas de madera y alambre para orear los ajos, que se basaba en criterios económicos y técnicos simultáneamente:

A Francisco Torres se le presentó la idea de orear mejor sus ajos de semilla para que no se le dañaran tanto en febrero de 1957. Esta idea es la de usar cajas de madera pequeñas con fondos de malla y alambre para permitir el paso del aire (...) Hubo recepción positiva de la idea. Luego Fco. consultó con otros agricultores, como Rafael Álvarez, a quien poco se le dañan sus ajos, y estos le explicaron que les había dado resultado el poner los ajos en costales de papa, de tejido abierto, y cambiarlos de posición de vez en cuando y sacarlos a orearlos. Con esta alternativa, Fco. olvidó la idea nueva que implicaba también el trabajo de hacer las cajas y el gasto. Esta no iba a suplir la práctica actual en forma por lo visto mas eficiente. Fco. decidió seguir el consejo de sus vecinos. $\underline{6}$

Es interesante que, en sus notas de campo, Fals no solo da cuenta del rechazo a innovaciones con base en argumentos de tipo económico, sino también de motivaciones que ayudaban a comprender sus razonamientos y decisiones económicas. Es el caso del rechazo que hacían los campesinos, con base en una evaluación de la oferta y la demanda, a la propuesta de combatir la gota de los ajos, que según Fals obedecía a falta de visión frente a posibilidades de apertura de nuevos mercados y mejoramiento de procesos de distribución y transporte del ajo.

No quieren los campesinos que se mejore el ajo y que se combata la gota porque así habría más semilla, más producción y con el consiguiente abaratamiento. Dicen que es mejor que se dañe a que se baje el precio. Hay poca visión de abrir nuevos mercados y fomentar la distribución y transporte, para aumentar el consumo. Así sí se justificaría más producción ${ }^{7}$.

Así, Fals reconoce criterios inteligentes utilizados por los campesinos sin dejar de conectarlos con otro tipo de causas. 
En sus notas sobre la introducción de un cambio en la forma de lavar la ropa hay también una referencia a razones que podrían entenderse como unas de tipo técnico, y que explicarían una adopción parcial por parte de doña Saturnina Sánchez de esta propuesta:

Francisco construyó un puesto para que su mamá lavara al lado de la casa y el pozo nuevo: le hizo una enramada contra el viento y la lluvia. La mamá ensayó el nuevo arreglo en vez de ir a lavar al pozo al otro lado del río, pero no le gustó mucho porque: 1) El agua parece que mancha de amarillo la ropa blanca (quizás por la caneca), también la lana lavada queda amarilla o gris; 2) No le gusta tener que echar el agua poco a poco, prefieren el chorro continuo del pozo tradicional, que permite enjuagar mejor.

Temporalmente se ha decidido lavar aquí la ropa de color y allá la blanca. $\underline{8}$

Un último asunto a resaltar sobre las resistencias tiene que ver con el concepto alianzas estratégicas de Wynne, referido a las relaciones que los campesinos establecen con los expertos siempre y cuando las mismas les representen beneficios (2004). En el siguiente fragmento, Fals se refiere a la capacidad de cambio de las mujeres boyacenses argumentando que su apertura a innovaciones estaba condicionada en parte por la respuesta que dieran a sus necesidades. "Las mujeres boyacenses también han demostrado ser permeables al cambio, cuando éste se fomenta con empatía y responde a una necesidad personal o colectiva” (Fals, 1958b, p. 232).

En este punto es oportuno señalar que a pesar de que fueron varios los programas dirigidos a mujeres, entre aquellos el que Fals impulsó en Saucío, es muy poca la reflexión tanto en notas como en publicaciones de Fals respecto a las resistencias de las saucitas frente a procesos de modernización. Esta limitación puede en parte explicarse porque las actividades agrícolas fueron el principal objeto de atención de Fals por estos años.

Doña Hilda Sánchez recuerda que no tuvo suficiente éxito el programa de máquinas de coser, una de las estrategias para la promoción de opciones laborales para mujeres que él impulsó, y que formaba parte de la Junta de Acción Comunal de la vereda a la cual me referiré posteriormente ${ }^{9}$.

\section{Figura1 10}

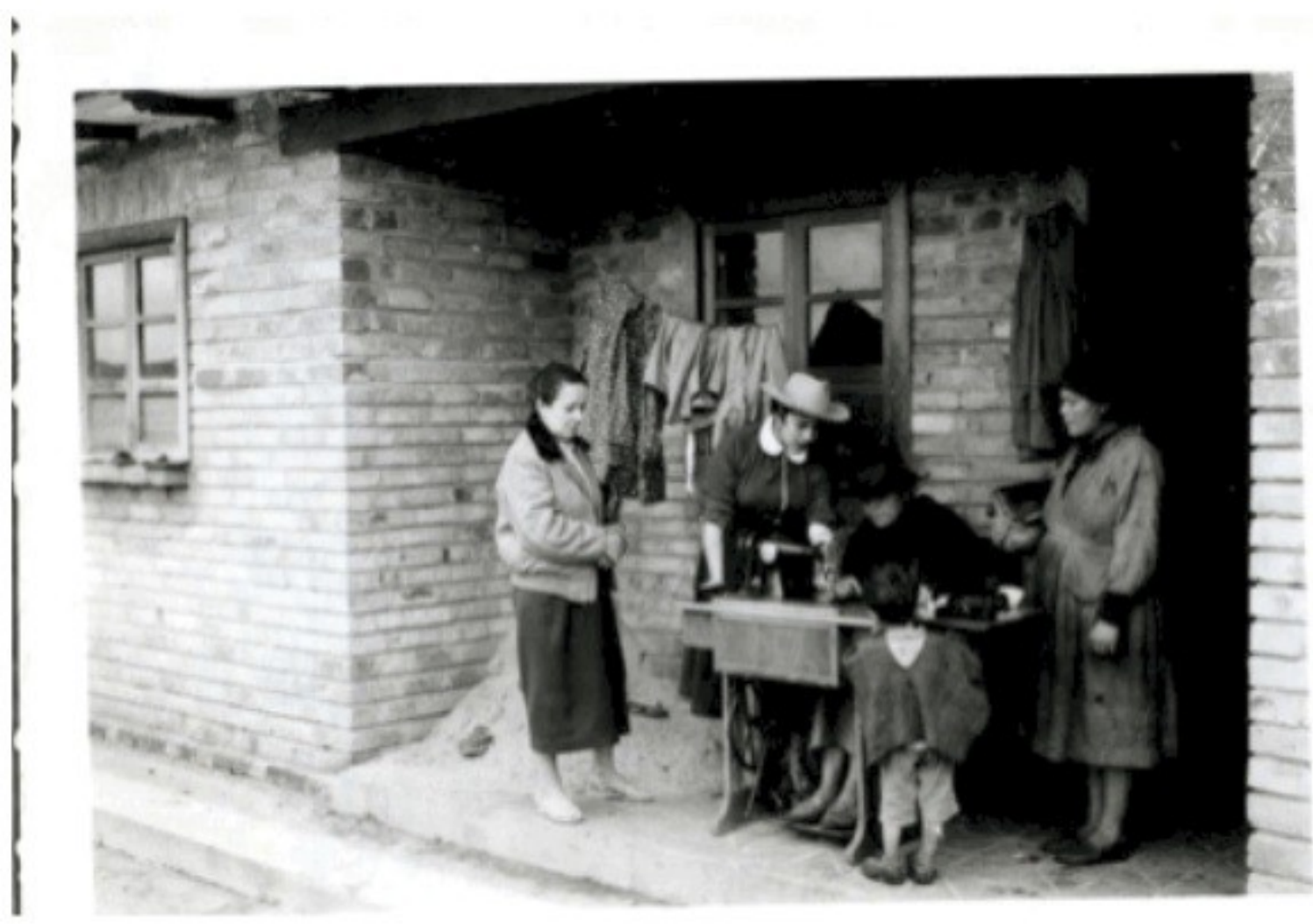


Para doña Hilda, quien fue la primera almacenista de la Cooperativa Agrícola veredal, el proyecto de las máquinas de coser fue fundamental para las mujeres saucitas, antes condenadas a una vida exclusivamente centrada en el

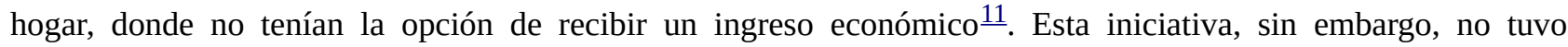
suficiente éxito según doña Hilda porque algunos maridos reclamaban a sus esposas el descuido de sus “obligaciones en el hogar”. Doña Hilda hace también una lectura de otros programas dirigidos a mujeres, o que incluían su participación, como el de la escuela rural, que daba cuenta de un gran interés de Fals en que las mujeres recibieran instrucción escolar, y de algunas iniciativas que no parecen haber procurado romper los parámetros de división de actividades por género, como la dirigida al arreglo de las alcobas en la vivienda rural a través de la fabricación casera de tocadores, y el curso que recibían sobre el bordado de pañales para bebés.

Doña Hilda recuerda además, entre las actividades promovidas por Fals, un programa de alfabetización y la llegada del cine a la vereda, y el entusiasmo que generaba en sus habitantes.

Llama la atención que acerca de los programas para mejoramiento de las condiciones de vida de la mujer, y de otros programas que Fals intentó introducir en Saucío, me haya enterado por doña Hilda y no por los hombres habitantes o exhabitantes de Saucío a quienes entrevisté. En mis conversaciones con los hombres de la vereda ellos no me dieron cuenta de estos dos últimos programas. Considero que esto se explica en parte por las preguntas que yo les hacía, reducidas a los programas agrícolas de Fals, pero también porque ellos estaban mucho más involucrados e interesados en los programas de cambio agrícola, siendo sus percepciones sobre lo que Fals hizo en Saucío, en ese entonces y ahora, distintas con relación a las de doña Hilda por su condición de género. Además, la ausencia de ese tema en la memoria de los saucitas hombres que conocieron a Fals puede estar relacionada con la tendencia a ver en las actividades promovidas por Fals aquellas que fueran de tipo productivo, donde no encajarían los programas dirigidos a mujeres, quienes tradicionalmente formaban parte exclusivamente del ámbito doméstico.

Es difícil afirmar que las actividades propuestas por Fals estaban completamente divididas por género porque, según don Julio Garzón, Rosa Delia Quintero de Bohórquez era miembro del equipo que participaba en procesos relacionados con la experimentación agrícola en Saucío $\underline{12}$. El caso de la introducción de máquinas de coser estaba en todo caso dirigido específicamente a las mujeres de la vereda y, al margen de que mis preguntas estuvieran en la mayoría de los casos dirigidas a averiguar sobre los experimentos y actividades agrícolas, la memoria de doña Hilda muestra rasgos distintos a la de don Francisco Torres, don Julio Garzón y don Carlos Julio Sánchez, a quienes entrevisté recientemente, y a la del propio Fals, teniendo en cuenta las referencias que hizo a las actividades que promovió en esta vereda en los cincuenta $\underline{13}$.

Demostraciones y adaptaciones

Hay que echar por tierra la idea de que estos campesinos son gentes irremediablemente conservadoras, incapaces de adoptar lo nuevo y aun de tener iniciativas valiosas. Ya hemos descrito lo sucedido en relación con la guadaña y con la zaranda para papas, cuando sencillos agricultores llegaron por sí mismos a soluciones de problemas técnicos, así como diversos casos de invención en otras actividades. (Fals, $1958^{\mathrm{a}}$, p. 481)

El problema mecánico de una zaranda experimental para papas fue resuelto por un saucita inteligente, llevándolo a adaptarla y promover su aceptación entre los otros agricultores (Fals, 2010, p. 74).

En este apartado trataré conjuntamente las categorías demostraciones y adaptaciones, presentes en las notas de campo de Fals por la interconexión práctica que tuvieron en los experimentos liderados por él. Como he mencionado, convencer a los campesinos acerca de la importancia de introducir cambios en sus prácticas y herramientas agrícolas no fue una tarea fácil para los modernizadores como Fals. Ante las resistencias naturales de los campesinos, para Fals fue fundamental poner en marcha estrategias que le permitieran "demostrar" las bondades de las novedades que proponía. La pregunta por los métodos efectivos para convencer a los campesinos acerca de la necesidad de introducir prácticas sociales, herramientas y técnicas agrícolas modernas, orientaba 
significativamente los experimentos promovidos por Fals.

La siguiente fotografía expresa su preocupación por encontrar formas efectivas de inducir la introducción de cambios tecnológicos en Chocontá, haciendo énfasis en la efectividad que tenían las "demostraciones en el terreno”, y en la importancia que tenía el que miembros de la comunidad utilizaran los artefactos nuevos ante el resto de habitantes de la vereda:

Figura $2 \underline{14}$

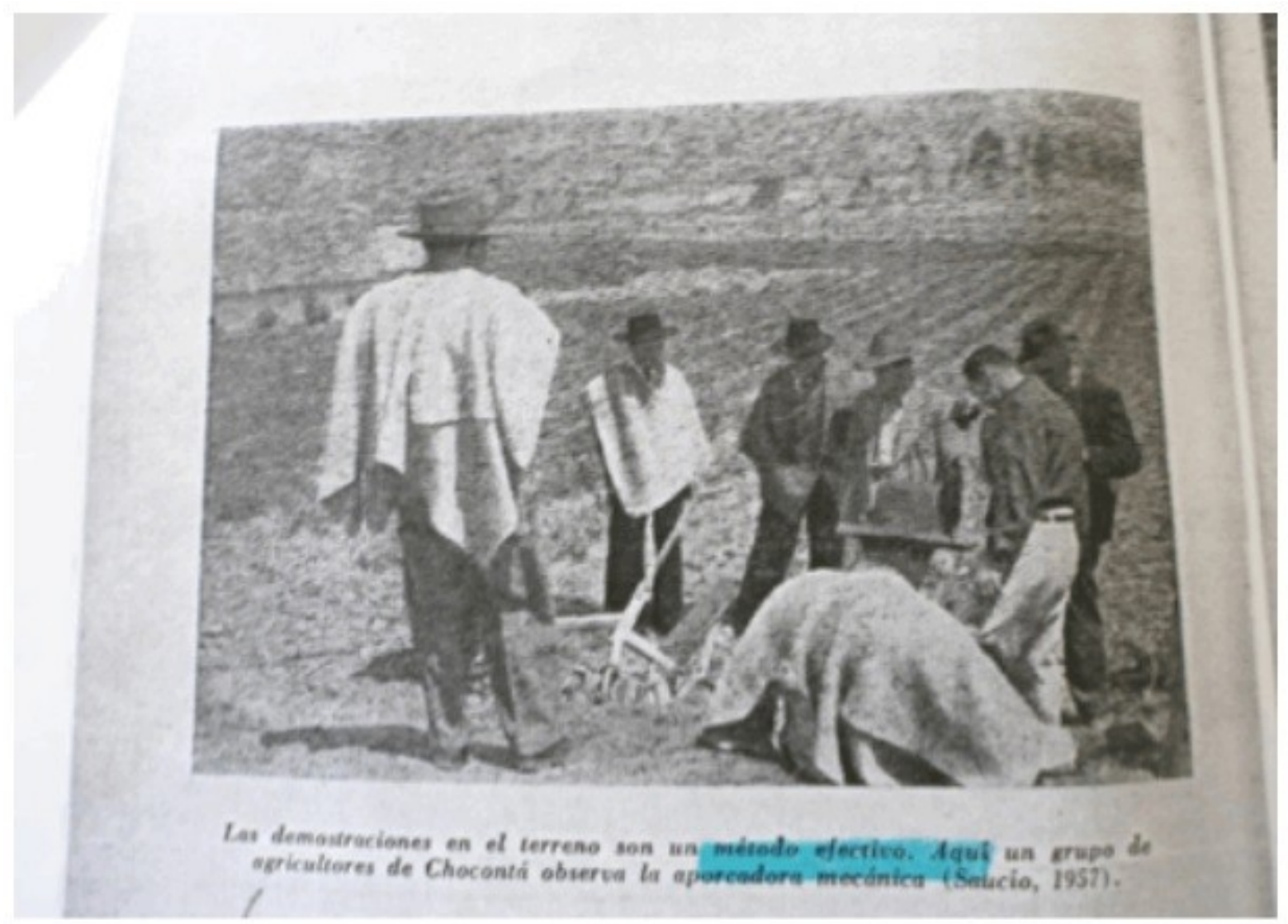

En este punto es relevante retomar a Shapin quien, concentrándose en las experimentaciones científicas del siglo XVI, sugiere que hay una relación inseparable entre el análisis de las condiciones físicas y las de tipo social de los experimentos (1988). Efectivamente, el hecho de que los experimentos promovidos por Fals se llevaran a cabo en el terreno y en público era clave entre las estrategias empleadas deliberadamente por Fals para convencer a los saucitas acerca de la importancia de introducir herramientas y técnicas modernas. Retomaré aspectos relacionados con las condiciones físicas más adelante.

Quienes manipulaban los instrumentos eran miembros de la comunidad local que se entrenaban en el manejo de los mismos hasta lograr una destreza satisfactoria, que se expresaba en la cantidad de tiempo y dinero ahorrado para cumplir una tarea agrícola, y en el momento en que a través de la demostración pública hacían evidente el aumento de la productividad que el uso de determinado artefacto significaba frente a aquel que tradicionalmente había sido empleado.

La reducción de los costos de producción, la forma por excelencia de dar cuenta de la efectividad y generación de productividad final de un aparato o técnica moderna, ocupó un lugar fundamental, no solo en los experimentos promovidos por Fals, sino en sus escritos académicos. Durante los años cincuenta elaboró al menos dos artículos centrados en este problema que, planteaba Fals, en Colombia no había sido objeto de reflexión suficiente. En los citados escritos académicos los costos de producción de determinado producto cultivado en Saucío eran comparados constantemente con los estándares de producción de Estados Unidos (Fals, 2010a). 
Los entrenados, como eran denominados por Fals quienes en las "demostraciones" se convertirían en entrenadores de sus paisanos, aprendían a manipular las herramientas a través de largas jornadas de ensayos de las cuales llevaba registro Fals, en ocasiones bajo la instrucción de expertos. $\underline{15}$

Un elemento que daba cuenta del éxito de los experimentos puestos en marcha, el progreso en la manipulación de las herramientas, era registrado por Fals en sus notas y en sus informes al Servicio Técnico ColombianoAmericano y al Instituto de Investigaciones Tecnológicas $\underline{16}$. Como sucedía con el resto de saucitas, "los entrenados” solían tener dudas sobre la importancia que tenía introducir herramientas agrícolas modernas, que Fals estaba interesado en identificar y disolver $\frac{17}{}$.

Fals igualmente buscaba que los entrenados conservaran el interés en llevar a cabo su tarea de entrenarse y demostrar, un objetivo que se lograría en la medida en que las herramientas mostraran su efectividad y que se alcanzara destreza en el manejo de las mismas $\frac{18}{}$.

El objeto de las demostraciones en terreno no era exclusivamente dar cuenta de la utilidad de los aparatos o prácticas e identificar resistencias frente a los mismos, sino también encontrar posibles fallas en las innovaciones que se proponían. A cada proyecto de introducción de un artefacto o práctica correspondían varias demostraciones, que se esperaba permitieran hacer ajustes en talleres del Instituto de Investigaciones Tecnológicas por parte de miembros del mismo o en la vereda por parte de los propios saucitas. Esto último da cuenta de cómo miembros del Instituto de Investigaciones Tecnológicas, el Servicio Técnico Colombiano-Americano, Fals y los saucitas, participaban en las demostraciones y en actividades relacionadas cumpliendo tareas de manera independiente. Hay sin embargo evidencias de tareas elaboradas conjuntamente por estos actores. Preguntarse por el material que podría servir para que una herramienta diera mejores resultados, fabricar de nuevo un aparato, supervisar la construcción del mismo y probar la efectividad alcanzada luego de este tipo de procesos, son ejemplos de tareas que en varios casos eran compartidas por los participantes de los experimentos.

En términos generales, las actividades alrededor de las demostraciones implicaban un fuerte trabajo en equipo, en el que las funciones de sus participantes eran variadas e intercambiables y un frecuente contacto cara a cara era imprescindible. El siguiente grupo de tareas que desempeñaron miembros de las demostraciones ilustra un poco más la dinámica de estos procesos: el propio Fals supervisaba personalmente adaptaciones a los implementos; los campesinos constantemente comentaban, sugerían y aplicaban cambios; John Farmer, del Instituto de Investigaciones Tecnológicas, no solo fabricaba las herramientas sino que las adaptaba; Eugene C. Reichard, del Servicio Técnico Colombiano-Americano, a quien con mucha frecuencia Fals enviaba informes sobre los experimentos que coordinaba en Chocontá, fue quien sugirió usar neumático en la primera adaptación de una zaranda de papas; Henry Allpress, también del Servicio Técnico Colombiano-Americano y jefe del proyecto del que Fals dirigía un programa, daba en una ocasión instrucciones en el terreno a un campesino saucita sobre el manejo de una de las herramientas que buscaban introducir $\underline{19}$.

En su exposición del proceso de introducción de la Zaranda de papas, Fals se refería a la adaptación de esta herramienta a manos de un saucita y a la recepción y fabricación de la misma por parte de un ingeniero. El siguiente fragmento muestra la centralidad de la interacción, a la que en este caso Fals denomina "colaboración" entre actores que participaban en los experimentos:

...Ocurrió entonces algo inusitado, que a su vez nos llenó de orgullo y esperanza. Uno de los campesinos presentó un diseño hecho por él mismo y discutido con sus compañeros, que utilizaba el principio del cuadrado para la clasificación de la papa. El ingeniero norteamericano inteligentemente recibió el diseño, lo estudió y aceptó, procediendo enseguida a llevarlo a la práctica. Dos nuevas zarandas de ensayo fueron el resultado de esta admirable colaboración entre la experiencia del campesino y la ciencia del ingeniero. (Fals, 1958 a p. 479).

Además de sostener contacto con campesinos, con el Instituto de Investigaciones Tecnológicas y el Servicio 
Técnico Colombiano-Americano en su coordinación de los experimentos, Fals se comunicaba y adelantaba actividades en colaboración conmiembros de estaciones experimentales estadounidenses asociados simultáneamente, en algunos casos, con instituciones académicas estadounidenses y con comerciantes de productos agrícolas $\underline{20}$. Estos interlocutores de Fals, sin embargo, no aparecen en los documentos revisados interactuando con los campesinos o miembros del Instituto de Investigaciones Tecnológicas y del Servicio Técnico Colombiano-Americano distintos a Fals.

Junto a los asistentes humanos, la presencia y el papel jugado por los bueyes era esencial así como la relación entre estos animales, las herramientas y los habitantes de la vereda: "Sin el yugo de cacho, los bueyes, desacostumbrados, se niegan a trabajar con el de collar”르.

Como anotaba, eran varias las demostraciones que solían hacerse para los experimentos con determinado aparato o práctica, y la función de las mismas era en buena medida dar lugar a la identificación de fallas que podrían tener los artefactos o las técnicas. Las demostraciones eran los momentos en que dudas, críticas, sugerencias y percepciones en general eran manifestadas, a las cuales seguían procesos de modificación en que intervenían campesinos y/o miembros del Instituto de Investigaciones Tecnológicas y del Servicio Técnico Colombo Americano, incluido en varias ocasiones el propio Fals $\underline{22}$. Las adaptaciones hechas a los artefactos conllevaban a una nueva demostración.

Una vez que determinado artefacto o práctica había demostrado ser lo suficientemente útil y tener grandes posibilidades de desplazar a sus predecesores, es decir, cuando se reconocía que existían altas posibilidades de ser introducidos, se hacía una demostración pública final.

Estos detalles acerca de las demostraciones están presentes en las notas de terreno de Fals que solían estar acompañadas por archivos fotográficos que hacen evidente, aún más que sus notas, la sistematicidad con que se llevaban a cabo los experimentos.

El sitio donde se hacían las demostraciones tenía un papel fundamental. Dos parecen haber sido los lugares más comunes para adelantarlas: 1. Los talleres del Instituto de Investigaciones Tecnológicas donde se llevaban a cabo adaptaciones a herramientas que buscaban introducirse en Saucío. 2. Los lotes o terrenos prestados por algún miembro de la vereda a quien en cierto momento Fals denominó "cooperador", donde eran presentadas públicamente propuestas de Fals. En muchas ocasiones ese papel de cooperador fue cumplido por don Francisco Torres $\underline{\underline{23}}$. Los lotes o terrenos prestados por un “cooperador”, los lugares más usados en las demostraciones, eran escogidos cuidadosamente por Fals. Tamaño, cantidad de yerba, tipo de productos sembrados, inclinación y en general facilidad para el funcionamiento eficaz de determinado aparato o práctica que garantizara el éxito de los experimentos, eran algunas condiciones que Fals evaluaba antes de escoger un lugar donde llevar a cabo las demostraciones $\underline{24}$. La preparación del terreno para los experimentos liderados por Fals equivale a lo que Shapin y Schaffer llamaron tecnología material en su investigación sobre las experimentaciones en Inglaterra, pues como he mostrado implicaba una serie de convenciones para justificar la difusión de nuevas prácticas y herramientas modernas (2005). Al parecer, estas evaluaciones del terreno no comprometían la confianza de don Francisco y los otros campesinos en las demostraciones.

Ya he hecho referencia a la importancia que tuvieron las adaptaciones de las propuestas materiales o prácticas de Fals en Saucío. Vale la pena, sin embargo, ampliar la referencia a este rasgo, porque es el que muestra con mayor claridad la relación entre los experimentos promovidos por Fals y la forma en que este último planteó su cuestionamiento a la tesis sobre el conservadurismo irremediable de los campesinos colombianos. La participación activa de estos últimos en la modificación de los artefactos modernos da cuenta de la inteligencia y creatividad que Fals resalta, como lo ejemplifica la siguiente nota de terreno de Fals de 1958:

Como en experimentos de otras ciencias naturales, lo inesperado puede ocurrir y tener mucho valor también en las aventuras sociológicas. Con la guadaña sucedió que un día un obrero subió a cortar avena 
en un lote adyacente a una parcela de papa ya madura. Es la costumbre cortar la rama de la papa con la hoz cuando ella llega a la última etapa de madurez, poco antes de cosecharla. Luego de segar la avena con la guadaña, ocurriósele al muchacho hacer lo mismo con las ramas de la papa. Observó que cortaba bien, con comodidad y rapidez y le informó a su patrón. Al día siguiente éste organizó su propio ensayo: ordenó, en efecto, a un obrero que cortara ramas con la hoz mientras él hacía lo mismo con la guadaña. Pronto terminaba de "segar" tres surcos de papa, mientras que el otro no completaba sino el primero, y los resultados eran igualmente satisfactorios desde el punto de vista del corte y posición de las ramas desprendidas. (Fals, 1958 a, p. 472).

Recientemente don Francisco Torres recordaba su participación activa en adaptaciones llevadas a cabo en Saucío. "Yo me volví técnico en eso" decía, refiriéndose a los cambios que hizo en la cocina de la vivienda de su madre, en el marco de un proyecto para elevar el nivel de vida en la vereda con la introducción de la cocina chula, una estufa cuyo uso había sido promovido en India. El siguiente fragmento ilustra este proceso de modificación local $\underline{25}$.

La estufa fue modificada así: 1) para que diera más calor, no gastara tanto carbón o leña y fuera más fácil de prender, se levantó el piso de la candela, ahora está más pegado a las planchas; 2) se llenó el espacio del ángulo con adobe para hacer una plataforma o mesa donde poner ollas y platos; 3) se usó ladrillo cocido sólo en las partes que toca el fuego, y el resto, específicamente la base y paredes externas se usó adobe - así resultó más barato; 4) se adoptó el cenicero (propuesto en Guateque) y construido por el maestro que vino; 5) se le adaptó una puerta vieja que se encontró en Bogotá; 6) se pintó con cal. $\underline{26}$

\section{Figura $3^{\underline{27}}$}

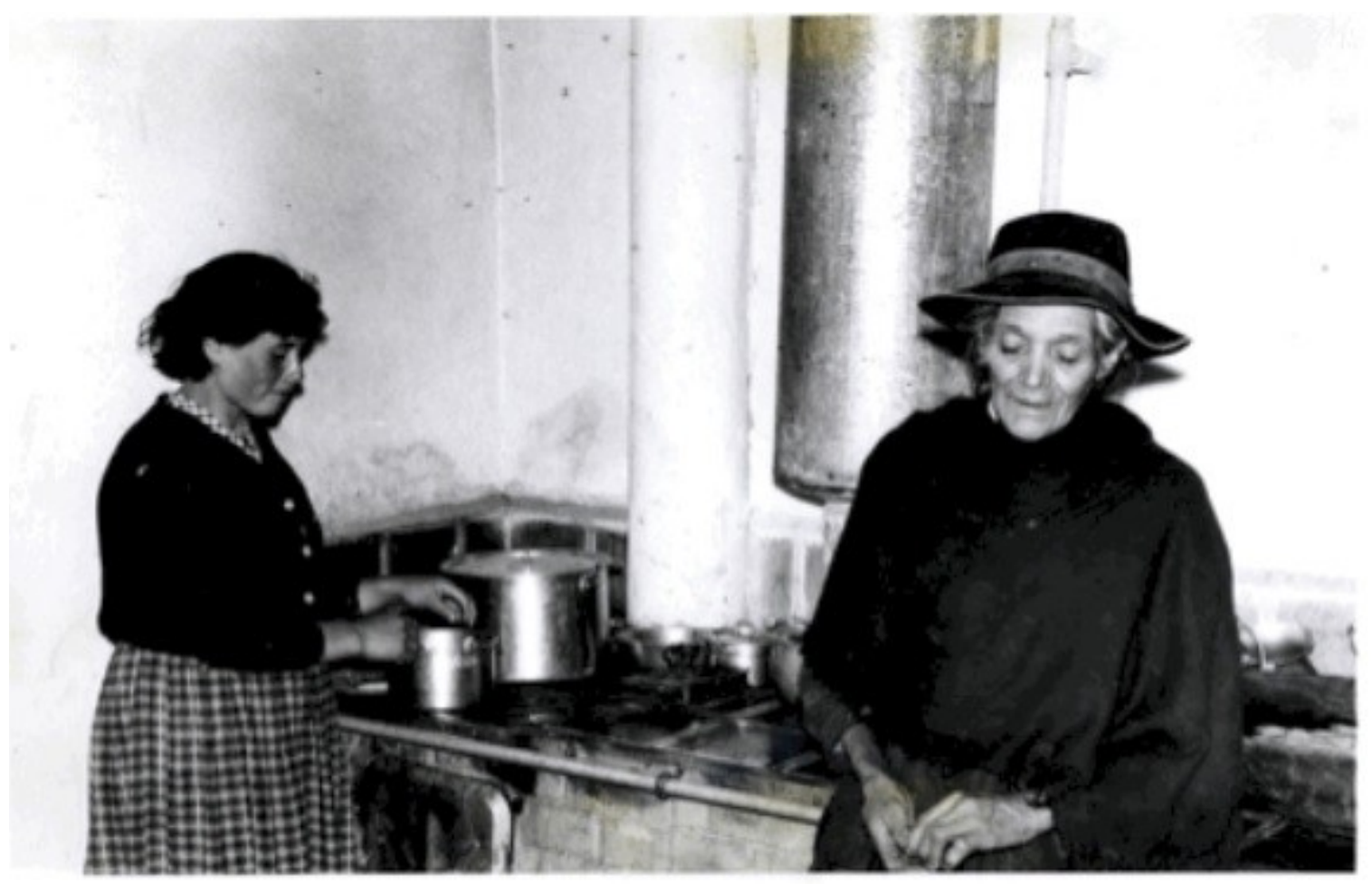

En la presentación del modelo institucional de cambio tecnológico, al inicio de este texto, puntualizaba que uno de sus rasgos era la importancia de involucrar a los locales en procesos de adaptación. Me he preguntado ¿por qué las adaptaciones tenían un lugar tan importante en estos proyectos?, y he encontrado dos razones: La primera de ellas es la tesis de la mecanización intermedia que consistía en hacer cambios agrícolas progresivos, no abruptos. Según la lectura que Fals presentaba en la versión de 1957 de su tesis doctoral, se trataba de un planteamiento que obedecía a evaluaciones internacionales sobre programas de introducción de maquinaria que procuraban producir, 
con inversiones muy altas, cambios drásticos en las técnicas tradicionales de cultivos. Tales experiencias habrían mostrado que la importación de maquinaria resultaba poco útil en muchas ocasiones, cuando no se consideraban los que Fals denominaba "aspectos conexos":

...el salto del azadón al tractor lo han estado pagando con creces casi todos los países que en forma inconsulta importaron las máquinas, sin haber tomado en cuenta los aspectos conexos de facilidades de transporte y mantenimiento, existencias de repuestos y talleres, personal idóneo para manejar y reparar las máquinas, formas de tenencia de la tierra, tamaño de las fincas, tipos de suelo, características del producido agrícola y cantidad y ocupaciones de la mano de obra local. (Fals, 1958a, p. 465).

Hacia 1958 la tesis de la mecanización intermedia era una política nueva de la Organización de las Naciones Unidas para la Alimentación y la Agricultura (FAO), entidad para la cual Fals trabajó durante ese año en Brasil, que tenía como aliado central al ya mencionado Instituto de Investigaciones Tecnológicas en Colombia $\underline{28}$. Tal tesis era una de las sugerencias planteadas por Smith, director de la tesis doctoral de Fals y reconocido sociólogo ruralista estadounidense, y era defendida en 1963 por Shumacher, quien para entonces incluía elementos ambientales y evaluaciones críticas de los esfuerzos por aumentar la productividad en países en desarrollo (1983a).

En 1955, Fals sugería a Helen Bjorkund no pretender abolir el consumo de guarapo abruptamente en Saucío, algo que puede interpretarse como indicio de la aplicación tanto de herramientas como de prácticas e ideas que tuvo como estrategia para hacer cambios progresivos, tan central en la tesis de la mecanización intermedia $\underline{29}$.

La segunda razón que me ha mostrado la importancia de la adaptación en los experimentos de Fals tiene que ver con los resultados positivos que, en términos de introducción de herramientas y prácticas modernas, generaba este procedimiento, como lo indica el siguiente fragmento sobre campañas de vivienda en que Fals se involucró en los años cincuenta: "Cabe relievar que según parece es en el mejoramiento de las casas actuales, no en la simple construcción de nuevas, donde radica el secreta del éxito en las campañas de vivienda” (Fals, 1956ª, p. 222).

Las adaptaciones en los experimentos de Fals estaban precedidas por un análisis de la funcionalidad de los artefactos o prácticas que se usaban. Es decir, cada adaptación era precedida por un estudio de aquellos elementos lógicos, razonables, inteligentes, que explicaban por qué entre los campesinos habían persistido, muchas veces durante un largo tiempo, ciertas ideas, prácticas, herramientas o artefactos. Esta evaluación marcaba el límite entre lo que debía procurar cambiarse y lo que valía la pena que permaneciera. Fals planteaba que muchas veces la persistencia de ciertas ideas o materiales se explicaba porque estos respondían a necesidades importantes. En su interés por mejorar la vivienda rural en Colombia, antes de buscar la introducción de materiales distintos de la vivienda, Fals analizaba la funcionalidad de aquellos usados por los habitantes, con lo cual una vez más se reconoce la validez e inteligencia de las decisiones, prácticas y, en general, de la forma de vida campesina:

En fin, lo ideal sería, desde el punto de vista de la psicosociología práctica, construir o adaptar no solamente una casa de tipo urbano para el campesino, como se hace actualmente, sino varias estructuras que canalicen y separen las funciones de Ia vivienda, especialmente aquellas que se refieren a la defensa de los bienes y a depósitos. Está visto que estas funciones (que hacían parte de las que había encontrado Fals en la vivienda rural antes de proponer la implementación de cambios en ella) son imprescindibles en la vivienda rural (Fals, 1956b, p. 226).

\section{Difusión}

En su interés por poner en marcha experimentos, Fals prestaba una especial atención a la forma en que se daban los procesos de difusiónde herramientas, prácticas agrícolas y/o de artefactos e ideas relacionados con el nivel de vida en Saucío. ¿Quién o quiénes habían actuado como fuentes de difusión?, se preguntaba. Por ejemplo, para el caso de la introducción del pozo de agua, daba cuenta de las condiciones en que podría difundirse el mismo, a saber, cuando la experiencia de un habitante de la comunidad fuera exitosa. 
Entre los interesados en abrir pozo se encuentra Santiago Deaza, uno de los clientes del hermano Benedictino (?) que vino a descubrir el agua en julio (?) de este año. Santiago esperó hasta el comienzo del verano, ahora en diciembre, para abrir su pozo (...) Ya lleva 10 metros y espera llegar a 12 1/2 para ver si sale agua y lo que dijo el hermano fue verdad. La capa en que está ahora es arenosa. Una vez que Santiago descubra el agua, los otros clientes del hermano harían sus pozos $\underline{30}$

Además de atender detalladamente a la manera en que se daban o facilitaban los procesos de difusión en la vereda, Fals ideaba estrategias de difusión. Aunque no tiene que ver directamente con un determinado experimento promovido por Fals, el comunicado que en 1955 enviaba a Helen Bjorkund, sobre la oportunidad de llevar a cabo en Saucío una campaña para promover el consumo de agua hervida, ejemplifica la manera en que ideaba formas de difusión. Luego de presentar con detalle las creencias que los saucitas tenían acerca del agua, Fals sugería a Bjorkund usar una de esas creencias para mostrar la necesidad de hervir el agua. La campaña que Fals planteaba a Bjorkund incluía también el uso de películas y material audiovisual $\underline{31}$.

En su interés por lograr la difusión de sus iniciativas, Fals relevaba la importancia de las “compañías”, que consistían en uniones entre varias personas para cultivar (Fals, 1961). Con base incluso en su propia experiencia, pues en algún momento formó una compañía con Don Francisco, encontraba en esas formas de asociación una tendencia a comunicar los beneficios obtenidos y así una fuente clave de difusión de sus propuestas.

Las compañías de agricultura sirven para difundir nuevas prácticas, si resulta que uno de los socios sabe de alguna y no es egoísta. La tendencia es de comunicar, en vista de que participarán de los beneficios. Así ha sucedido entre Fco. y yo, y ahora entre Fco. y José Castro. Este es un buen cultivador del ajo en grande en la finca de su papá en Puebloviejo y ha hecho innovaciones (con el papá): uso del sulfato de amonio como abono para el ajo cuando está creciendo, uso de un rastrillo de jardín de diente largo para picar, y una nueva forma de sembrar los dientes de ajos dejándolos caer en grupo y no individualmente que es lo corriente. Todo esto ha enseñado José a Fco., quien ya consiguió su rastrillo. $\underline{32}$

Llama la atención que en Saucío se difundían usos de los productos distintos a aquellos para los que se destinaban inicialmente por los productores de insumos agrícolas. Como puede observarse en el siguiente fragmento, el sulfato de amonio en las instrucciones era presentado como producto para habas y maíz, pero fue usado con buenos resultados para el ajo y con malos resultados para la papa.

Los Castro de Puebloviejo ensayaron un abono de sulfato de amonio para los ajos, desde hace 3 años. Este abono fue traído por el Sr. Ramón Gómez, hacendado de Chocontá, amigo de los Castro, para echarle a la papa. Pero no resultó para papa [En las instrucciones se lee que sirve para maíz y haba]. Gómez le regaló un bulto al Sr. Castro (Agapito y su hijo José) para ensayar con los ajos [Son ellos los que mejor siembran el ajo en Chocontá]. El primer año le echaron el abono poco tiempo después de sembrar. Llovió y parece que con la reacción con las sales quemó la raíz y dio poco. Al segundo año echaron el abono un poco más tarde, cuando ya la mata estaba más crecida. Este sistema les dio magnífico resultado, pues los ajos engordan muchísimo. $\underline{33}$

Como puede verse en el anterior fragmento, en la experimentación con sulfato de amonio en ajo el proceso de identificación de explicaciones a las fallas iniciales y los consiguientes ensayos tardaron tres años. Por esta y otras notas, que incluyen en su título la categoría difusión, es posible saber que la duración de los experimentos llegó a ser en ocasiones larga.

A inicios de los años sesenta, a manera de evaluación de sus actividades de investigación y experimentación en Saucío, y motivado por el interés persistente en formas efectivas de difusión de iniciativas modernizadoras, Fals publica un trabajo sobre la comunicación de ideas entre campesinos con Paul Deutchman, miembro de la Fundación Rockefeller, con financiación de esta última entidad. Fals y Deutchman planteaban en su investigación que en Saucío existía una tendencia a innovar que duplicaba la de Estados Unidos. De este modo, Fals confirmaba la observación que desde mediados de los cincuenta había hecho sobre la capacidad creativa de los Saucitas $\underline{34}$. 
Hasta aquí he mostrado cómo los experimentos liderados por Fals consistían en una serie de procesos que no necesariamente se daban siempre de la misma manera: propuesta de introducción de nuevas prácticas, ideas o herramientas teniendo en cuenta la funcionalidad de aquellas que se tenían y usaban previamente; identificación de las razones (técnicas o económicas, por ejemplo) por las cuales se rechazaba una propuesta parcial o totalmente; presentación de argumentos convincentes en terreno sobre la utilidad de las propuestas; ensayo y adaptación de artefactos y prácticas, con la participación imprescindible de los campesinos; estimulación de la capacidad de trabajo comunal para potenciar la comunicación de experiencias exitosas de cambio.

Creando comunidad

En el contexto de expansión de la sociología rural de la segunda posguerra, interesado en identificar diferencias entre distintas zonas rurales del mundo que permitieran implementar y evaluar estrategias diferenciadas de desarrollo, de acuerdo a especificidades organizativas rurales, Smith planteaba que era necesario crear y fortalecer “comunidades rurales” en lugares donde las casas rurales estuvieran muy dispersas, como en el caso de Estados

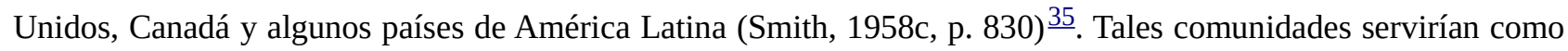
base para la promoción de esfuerzos colectivos, el fortalecimiento de una mentalidad capitalista entre los miembros de las comunidades, lo que permitiría que una persona cooperara con su capital en un negocio, y la introducción de métodos de producción agrícola que economizaran trabajo humano. En este enfoque era fundamental la existencia de instituciones (familiares o educativas, por ejemplo) que permitieran a los miembros de la comunidad satisfacer sus necesidades, para cuya construcción era fundamental el empleo de esfuerzos locales con el objetivo de que las iniciativas no fueran extrañas y estuvieran al alcance de las comunidades rurales de cualquier lugar del mundo. Para Smith la creación de comunidad y la consecuente cohesión que la misma generaría, permitiría llevar a cabo cambios sociales y técnicos que, al satisfacer a su vez necesidades o elevar el nivel de vida, motivarían la continuidad de esfuerzos colectivos de cooperación (Smith, 1980, p. 36)

De manera similar a la perspectiva de Smith que acabo de describir, en su promoción de los experimentos agrícolas y de nivel de vida, particularmente en su consideración sobre la capacidad que los campesinos tenían para realizar cambios, Fals creía que jugaba un papel esencial la participación de los campesinos en el desarrollo de proyectos colectivos, y consecuentemente en la creación de conciencia cooperativa. Para Fals era importante que se generaran estímulos para crear la capacidad de trabajar colectivamente, superando tendencias individualistas. Con relación a los campesinos boyacenses, anotaba en la versión de 1957 de su tesis doctoral que, pese a la dispersión de sus casas, era posible crear actos comunales ${ }^{37}$.

Para muchos observadores este patrón de asentamiento en granjas dispersas es una de las causas del notable individualismo del campesino boyacense. (...) Pero si se observa luego el funcionamiento de este tipo de poblamiento, habría que admitirse que promueve la falta de sociabilidad, el retraimiento, la reserva y la timidez. Es una de las causas de que el campesino piense más en sí mismo que en la comunidad, es decir, lo torna en un egocéntrico, lo confirma en su individualismo básico. Sin embargo, no es esta razón para pensar que el campesino boyacense no pueda participar en actos comunales. Ya se explicó que existen costumbres tales como el convite que dicen de una tendencia a la cooperación. El sentido cooperativo apenas está atrofiado; siendo resultado de un proceso educativo, puede perfectamente fortalecerse por medio de campañas y líderes hábiles. En este sentido es mejor ir despacio y organizar compañías de dos personas o cooperativas de tres o cuatro ... para la compra de maquinaria por parte de agricultores pequeños (Fals, 1957ª p. 205-206).

Para Fals la idea de un campesino boyacense abierto a técnicas y herramientas modernas estaba fuertemente entrelazada con la convicción acerca de su capacidad de trabajo comunal y de la posibilidad de fortalecerla. Así, trabajar en la creación de actividades cooperativas redundaría en oportunidades para generar cambios en la vida rural.

A finales de los años cincuenta, los experimentos fomentados por Fals formaron parte fundamental de la dinámica 
de una institución inicialmente veredal y posteriormente municipal, de cuya creación y puesta en marcha también fue promotor y líder Fals: la Cooperativa Agrícola de Saucío creada en 1958, una institución que, según la lectura que hace hoy don Francisco Torres, fue exitosa mientras sus miembros tuvieron claro que la motivación principal de su participación en dicha institución era el beneficio veredal $\underline{38}$.

La cooperativa agrícola funcionaba como un medio efectivo para convencer a los campesinos acerca de la necesidad de introducir herramientas y prácticas agrícolas nuevas, incluyendo el uso de semillas, variedades y fertilizantes antes desconocidos en este lugar $\underline{\underline{39}}$. La dinámica de la cooperativa estaba estrechamente relacionada con la granja experimental de Tibaitatá ${ }^{40}$. En esta última se adelantaban experimentaciones en las que participaban las personas más cercanas a la cooperativa, incluyendo el presidente, el tesorero y el secretario, y una vez que se obtenía un resultado "satisfactorio", que de acuerdo al modelo de cambio tecnológico era el aumento de la productividad, se ofrecían "clases" en la vereda dando instrucciones para poner en marcha proyectos agrícolas (como el de la "papa Saucío”, con la cual se experimentó en la granja de Tibaitatá previamente a su cultivo y comercialización). Esa papa tuvo una productividad muy alta en comparación con la de la papa que solía

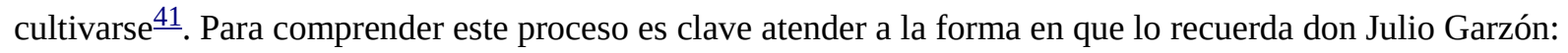

...hicieron un injerto [que] se llamó la papa Saucío ... y eso fueron hasta ... Tibaitatá ... allá iba [se refiere a OF] con mi compadre [se refiere a Don Francisco] y la finada Rosadelia [habla de Rosadelia Quintero de Bohorques, quien según Don Julio participó muy de cerca en los proyectos de la JAC] ... y luego ya llegaban y nos daban las instrucciones para que supiéramos todo lo que se estaba haciendo. ... La papa Saucío nos vino dando un buen resultado porque de una carga daba hasta cuarenta, cuarenta y dos cargas. ... $\underline{42}$

Además, a través de la asociación de algunos habitantes en la cooperativa agrícola veredal, también con la intervención de Fals como mediador y promotor principal, se diseñó en 1964 un proyecto de exportación de ajo a empresas de Nueva York, con las que se estableció contacto en el marco de la Alianza para el Progreso y para las que se había adelantado un estudio sobre producción de ajo en Chocontá. Tal estudio era el primero de carácter técnico en Colombia sobre un producto hortícola y se realizó con el apoyo del Instituto de Investigaciones Tecnológicas de la Caja Agraria $\frac{43}{3}$. Parece adecuado señalar una relación entre cálculos que Fals llevó a cabo en sus primeros años en Saucío y que aparecen en su tesis de maestría acerca del rendimiento del ajo y este proyecto. Señalaba Fals en su apartado "Rendimientos de los productos agrícolas en 1950", del capítulo sobre agricultura intensiva de esa monografía, que el ajo salía bien librado al comparar su rendimiento con el normal para el caso estadounidense, lo cual indicaba que esos cultivos “seguros” merecían atención. Es decir, la evaluación que hacía en su trabajo sobre rendimientos agrícolas sirvió como una especie de análisis previo de mercadeo que permite entender por qué fue un proyecto de exportación de ajo, y no de otro producto, el que se impulsó. El documento con la propuesta de exportación de ajo sugería que la dinámica de ese proyecto debía incluir apoyo a los agricultores para la introducción de variedades de ajo, técnicas de cultivo, y la construcción de una granja experimental sobre ajo en Chocontá (Fals, 1961).

La cooperativa agrícola veredal facilitaba a sus miembros la obtención de créditos con la Caja Agraria, una de las entidades más importantes de la institucionalidad y de la implementación de la política agraria colombiana de esos años, con los precios más bajos de insumos agrícolas. Además, la cooperativa permitió conseguir un tractor que se alquilaba entre sus miembros. Según Don Julio Garzón, aún los habitantes de la vereda que en un comienzo desconfiaban de los proyectos de la cooperativa terminaron introduciendo sus propuestas $\underline{44}$.

La cooperativa era a su vez uno de los frutos de la creación de la Junta de Acción Comunal de Saucío en 1958, en cuya creación y desarrollo había sido central también Fals. Tal junta era la primera con personería jurídica en el país $\underline{45}$.

Los experimentos y el resto de actividades promovidos por Fals en Saucío han hecho que en muy buena medida 
sea recordado gratamente por sus habitantes. Si bien se trataba de iniciativas modernizadoras que partían de supuestos como el atraso cultural de esta vereda, los proyectos de Fals rompían esquemas generando entre sus miembros expectativas y evaluaciones muy positivas, recordadas aún hoy cuando han pasado más de cincuenta años. La referencia de don Julio Garzón a Fals como un “colaborador” e "iniciador” de distintos programas que implicaban un trabajo colectivo con beneficios para los saucitas, ilustra un poco la percepción general que tienen sobre este personaje y sus propuestas algunas personas que lo conocieron $\underline{46}$.

La idea de extender los experimentos al contexto nacional

La importancia de los experimentos que Fals adelantó entre 1956 y alrededor de 1958, particularmente aquellos que promovió cuando trabajaba con el Servicio Técnico Colombiano-Americano y el Instituto de Investigaciones Tecnológicas, obedece en parte a que estos formaron parte de un programa piloto del Instituto de Investigaciones Tecnológicas que se buscaba extender a otras partes de Colombia (Fals, 1958a, p. 482). Según Fals, las condiciones en que estos experimentos se llevaban a cabo en Saucío, Veracruz y Boquerón, veredas del municipio de Chocontá, compartían rasgos típicos de desarrollo socioeconómico del país (Fals, 1958ª, pp. 467, 482).

Poner en marcha experimentos que promovieran la introducción de prácticas y herramientas agrícolas modernas en este tipo de lugares estaba para Fals justificado en los ahorros significativos de recursos materiales y humanos que se generarían; esto se explicaba porque eran este tipo de habitantes con quienes se llevaban a cabo estas iniciativas, y quienes producían la mayor parte de los artículos agrícolas de Colombia. Por lo anterior, impulsar programas de adaptación de maquinaria en haciendas y porciones limitadas del país no generaría la misma utilidad. Con la aspiración de replicar la experiencia para el aumento de la productividad agrícola adelantada en Chocontá, en otras partes de Colombia se esperaba alcanzar un abaratamiento de los víveres que mejorara los problemas sociales en un nivel nacional; es decir, la misma estrategia sugerida por la CEPAL que cité al inicio de este texto, en la que se esperaba que el fortalecimiento de la producción nacional redundara en respuestas efectivas al crecimiento de la demanda de alimentos (Fals, 1958 a, p. 482).

Equilibrar la relación oferta-demanda debería ser el resultado de un programa nacional de introducción de herramientas agrícolas modernas caracterizado por una serie de rasgos: contar con un taller nacional para diseñar, producir y estudiar herramientas, así como para mejorar las que estaban usándose en ese momento en Colombia; coordinar las actividades del taller con ensayos en campo que permitieran trabajar de forma sistemática en la adaptación de las herramientas estudiando su eficiencia, receptividad o resistencias que guiaran y precedieran demostraciones y ventas; hacer equipos de demostradores que no solo mostraran la forma de usar los equipos mejorados, sino también la forma de obtener los mismos y la manera de utilizar créditos para este fin; crear mercado para estos implementos; una vez puestas las bases del mercado, que habrían ayudado a establecer los demostradores, autorizar a talleres y fábricas colombianas para la producción y distribución de las nuevas herramientas (Fals, 1958 ${ }^{\mathrm{a}}$.

\section{Conclusiones}

He analizado la relación entre la dinámica de los experimentos promovidos por Fals y su crítica a la idea de la pasividad campesina, que se dio en el contexto de la implementación del modelo institucional de cambio tecnológico. Mostré cómo con el método de experimentación por participación en que eran fundamentales las demostraciones en terreno, los procesos de adaptación de herramientas y prácticas, la identificación de resistencias y el análisis de formas de difusión, categorías presentes en las notas de campo de Fals, él dio cuenta de campesinos capaces, creativos, inteligentes y abiertos al cambio rompiendo así el mito de la supuesta pasividad inexorable de los campesinos, tan difundida entre las élites colombianas en ese momento. Di cuenta también de la conexión entre los experimentos promovidos por Fals y la idea de generar procesos de cohesión comunitaria, con el plan de extender a nivel nacional la modernización de prácticas y herramientas rurales. 


\section{Notas}

1 Este trabajo se ha realizado en el marco del proyecto "Relaciones Internacionales Tecnocientíficas de América Latina con Alemania y Estados Unidos durante el siglo XX” Códigos: 201010016521 y 13546. Es también un resumen de un capítulo de la tesis “Redes, Ideas y prácticas de Orlando Fals Borda. 1951-1974”, elaborada por la autora con la dirección de Alexis de Greiff. Doctorado en Ciencias Humanas y Sociales. Centro de Estudios Sociales. Facultad de Ciencias Humanas. Universidad Nacional de Colombia.

$\underline{2}$ Saucío es una vereda del municipio de Chocontá, departamento de Cundinamarca, ubicado en los Andes de Colombia. Carpetas Agricultura, Introducciones, Nivel de vida, Comunicación y Difusión ubicadas en Carpeta Acción Comunal - Saucío. AHUNC/B.

$\underline{3}$ Hacen parte de los apoyos externos para el caso colombiano los referidos en el siguiente fragmento: “...en 1958 se sentaron las bases definitivas para la separación de los instrumentos de formulación y ejecución de la política agropecuaria nacional... En su empeño por atender todos los aspectos necesarios para una mejor política agropecuaria, el Ministerio amplió y mejoró los programas con entidades extranjeras como la FAO, para el suministro de técnicos especializados; el BIRF, para la realización de estudios sobre problemas agropecuarios; la OEA, que facilitaría cursos de especialización de ciencias agrícolas, y el punto IV o Servicio Técnico Agrícola Colombo-Americano, cuya actividad principal sería la de extensión.” Ministerio de Agricultura, Caja de Crédito Agrario, Industrial y Minero, Departamento de Estudios Económicos y planeación financiera. (1977b), p. 3.

4 Smith hacía uso de este concepto refiriéndose por ejemplo al grado de cohesión en los sistemas sociales como un factor en la resistencia al cambio social. (Ver también Holmberg, A.,1954, pp. 103-113).

$\underline{5}$ Carpeta Ajos, Maíz, Fríjol 1955-1964, Carpeta Agricultura, Carpeta Acción Comunal-Saucío, AHUNC/B.

6 Carpeta Ajos, Maíz, Fríjol 1955-1964, Carpeta Agricultura, Carpeta Acción Comunal-Saucío, AHUNC/B.

ZCarpeta Ajos, Maíz, Fríjol 1955-1964, Carpeta Agricultura, Carpeta Acción Comunal-Saucío, AHUNC/B.

$\underline{8}$ Carpeta lavandería, Carpeta Acción Comunal-Saucío, AHUNC/B.

$\underline{9}$ Entrevista de la autora a Doña Hilda Sánchez, 2012.

10 Sin datos sobre la fotografía. Probablemente la señora de la izquierda no era campesina y estaba encargada de promover la introducción de la máquina. Especulo al respecto basándome en su vestimenta y teniendo en cuenta que en las notas sobre la introducción de la cocina traída de india Fals da cuenta de la presencia de una mujer “mejoradora del hogar” de Servicio Técnico Colombiano-Americano.

11 H. Sánchez, comunicación personal, 2012.

$\underline{12}$ Entrevista a Don Julio Garzón por Mauricio Caviedes y Mónica Moreno, 2012.

13 Entrevistas de la autora a Julio Garzón, Carlos Julio Sánchez y Francisco Torres, 2012.

14 La foto aparece en Fals, O., 1958‥ . Subrayado mío.

$\underline{15}$ Carpeta Arado de vertedera, Carpeta Introducciones, Carpeta Acción Comunal-Saucío, AHUNC/B.

16 Memorando de Fals a Henry A. Allpress. Nov. 27 de 1956, Carpeta Guadaña, Carpeta Introducciones, Carpeta Acción Comunal-Saucío, AHUNC/B.

17 Memorando de Fals a Eugene C. Reichard, Nov. 12 de 1956, Carpeta Guadaña, Carpeta Introducciones, Carpeta Acción Comunal-Saucío, AHUNC/B.

18 Memorado de Fals a Eugene C. Reichard, Nov. 3 de 1956, Carpeta Guadaña, Carpeta Introducciones, Carpeta Acción Comunal-Saucío, AHUNC/B. 
19 Carpeta Zaranda para papas, Carpeta Introducciones, Carpeta Acción Comunal-Saucío, AHUNC/B. Al menos al 5 de abril de 1957 este era su cargo. Memorando de Fals Borda a Eugene C. Reichard, Abril 5 de 1957. Carpeta Arado de vertedera, Carpeta Introducciones, Carpeta Acción Comunal-Saucío, AHUNC/B. Carpeta Guadaña, Carpeta Introducciones, Carpeta Acción Comunal-Saucío, AHUNC/B.

$\underline{20}$ Carpeta Horticultura, Maíz, Fresas, Carpeta 1956-1961, Carpeta Agricultura, Carpeta Acción Comunal-Saucío, AHUNC/B.

$\underline{21}$ Mayo de 1959, Carpeta Yugo de Collar, Carpeta Introducciones, Carpeta Acción Comunal-Saucío, AHUNC/B.

$\underline{22}$ Memorando de Fals Borda a Eugene C. Reichard, Nov 12 de 1956, Carpeta Acción Comunal - Saucío. Carpeta Introducciones, Carpeta Acción Comunal-Saucío, AHUNC/B.

$\underline{23}$ Carpeta Guadaña, Carpeta Introducciones, Carpeta Acción Comunal-Saucío, AHUNC/B.

$\underline{24}$ Carpeta Guadaña, Carpeta Introducciones, Carpeta Acción Comunal-Saucío, AHUNC/B. Carpeta Arado de vertedera, Carpeta Introducciones, Carpeta Acción Comunal-Saucío, AHUNC/B.

$\underline{25}$ Entrevista de la autora a don Francisco Torres y a doña Hilda Sánchez, 2012.

26 Notas de Fals Borda sobre la introducción de una estufa traída de India. Feb 23 de 1957, Carpeta Cocina Chula, Carpeta Introducciones, Carpeta Acción Comunal-Saucío, AHUNC/B.

$\underline{27}$ Carpeta Acción Comunal Saucío, Carpeta Nivel de vida, Carpeta Cocina chula. Archivo Histórico.

$\underline{28}$ Sobre el trabajo de Fals Borda con FAO en Brasil en la carta de abril 12 de 1962 de Fals Borda al presidente de la Asociación Latinoamericana de Sociología, Alfredo Poviña, con que pedía su afiliación y la de Camilo Torres a la misma. Esa carta incluye una breve presentación de su recorrido profesional del que forma parte su trabajo con la FAO ante el gobierno brasilero en 1958. "VI Congreso Latinoamericano de Sociología”, Carpeta No 6, Caja 1440, ASCH/B. Ver también Fals, O., 1959. p. 78.

$\underline{29}$ Memorando de Fals Borda a Helen Bjorkund, Noviembre 28 de 1955. Carpeta Nivel de vida, Carpeta Acción Comunal-Saucío, AHUNC/B. Planteaba esta sugerencia con base en una investigación histórica sobre el tema que había hecho en esta vereda. Memorando de Fals Borda a Helen Bjorkund, Noviembre 28 de 1955. Carpeta Nivel de vida, Carpeta Acción Comunal-Saucío, AHUNC/B.

30 Diciembre 25 de 1959, Carpeta Nivel de vida, Carpeta Acción Comunal-Saucío, AHUNC/B.

31 Memorando de Fals Borda a Helen Bjorkund, Noviembre 28 de 1955. Carpeta Nivel de vida, Carpeta Acción Comunal-Saucío, AHUNC/B.

$\underline{32}$ Carpeta 1955-1964, Carpeta ajos, maíz, fríjol, Carpeta Agricultura, Carpeta Acción Comunal-Saucío, AHUNC/B.

$\underline{33}$ Carpeta 1955-1964, Carpeta ajos, maíz, fríjol, Carpeta Agricultura, Carpeta Acción Comunal-Saucío, AHUNC/B.

$\underline{34}$ Deutchman, P. y Fals, O. Comunicación de ideas entre campesinos, Carpeta 5, Caja 1413, ASCH/B.

$\underline{35}$ “Observaciones sobre la comunidad rural en América Latina”, T. Lynn Smith, 1955. Carpeta 1, Caja 1440, $\mathrm{ASCH} / \mathrm{B}$.

36 Sobre el modelo de cooperación reflexiona en términos teóricos e históricos en Smith, 1960.

$\underline{37}$ Boyacense es el gentilicio de quienes nacieron en el departamento de Boyacá -Colombia.

38 Entrevista de la autora a don Francisco Torres y doña Hilda Sánchez, 2012. 
$\underline{39}$ Entrevista a don Julio Garzón por Mauricio Caviedes y Mónica Moreno, 2012.

40 Tibaitatá es un municipio del departamento de Cundinamarca- Colombia. Entrevista a don Julio Garzón por Mauricio Caviedes y Mónica Moreno, 2012 y Entrevista de la autora a Francisco Torres, 2012. La granja fue creada en 1954 con asesorías de la misión Curie. (Machado, 2009a, p. 283).

41 Las clases también eran sobre semillas nuevas (Entrevista a Julio Garzón por Mauricio Caviedes y Mónica Moreno, 2012) Según Julio Garzón, en ocasiones quienes instruían en estas clases se habían desplazado desde Bogotá para ese fin.

42 Carta de Abdon Garzón y Juan de Jesus Robles (presidente del consejo de administración de la cooperativa agrícola de Saucío) dirigida a la Corporación Autónoma Regional, Carpeta 1, Caja 1452. ASCH/B.

43 Proyecto que probablemente no se llevó a cabo. Varias cartas escritas por Fals dan a entender que la cooperativa tuvo problemas para recibir préstamo de la caja agraria, necesario para poner en marcha este proyecto. Vale la pena agregar que en esta iniciativa no fue poca la importancia de la intervención directa y personal de Fals para facilitar la obtención de precios más bajos para los miembros de la cooperativa. Según Julio Garzón, Fals Borda respaldaba los miembros de la cooperativa para que pudieran acceder a créditos (Entrevista a Julio Garzón por Mauricio Caviedes y Mónica Moreno, 2012)

44 Entrevista a Don Julio Garzón por Mauricio Caviedes y Mónica Moreno, 2012.

45 Entrevista de la autora a Don Julio Garzón, Mayo de 2012; Copia del Acta de fundación de la Junta de Acción Comunal 1958 presentada por habitantes de Saucío a Orlando Fals en homenaje, 2008. Archivo personal de Julio Sánchez.

46 Entrevista de la autora a don Francisco Torres y doña Hilda Sánchez, 2012.

\section{Agradecimientos}

Agradezco las orientaciones de mi director de tesis Alexis de Greiff y de Joanne Rappaport. Además doy gracias a COLCIENCIAS quien financia mis estudios doctorales.

\section{Referencias}

Dagnino, R. (1979). Um novo enfoque do desenvolvimento e o papel da ciência e da tecnología. Sin más datos.

Fals Borda, O. (1956a). El campesino cundi-boyasense: conceptos sobre su pasividad. Revista de psicología, 1(1), 74-83.

Fals Borda, O. (1956b). Aspectos psico-sociológicos de la vivienda rural colombiana. Revista de psicología, 1(2), 206-229.

Fals Borda, O. (1961). Campesinos de los Andes. Estudio sociológico de Saucío. Bogotá. Universidad Nacional de Colombia.

Fals Borda, O. (1957a). El hombre y la tierra en Boyacá. Bases para una reforma agraria. Bogotá. Ediciones Documentos Colombianos.

Fals Borda, O. (1958a). Experimentos agro-sociológicos en Colombia. Revista Mito, 3(18), 465-482.

Fals Borda, O. (1958b). La dinámica de la extensión agrícola en Colombia: Observaciones sobre el cambio social inducido. Agricultura tropical, 14, 230-238.

Fals Borda, O. (2010a). Costos de producción agrícola en un minifundio: trigo y ajo. En Antología Orlando Fals borda. Colección Obra Selecta (pp. 25-36). Bogotá: Universidad Nacional de Colombia. 
Fals Borda, O. (2010b). La teoría y la realidad del cambio sociocultural en Colombia. En Antología Orlando Fals borda. Colección Obra Selecta. Universidad Nacional de Colombia (pp. 65-92). Bogotá: Universidad Nacional de Colombia.

Fitzgerald, D. (1994). Exporting American Agriculture The Rockefeller Foundation in Mexico, 1943-1953. En Missionaries of science The Rockefeller Foundation and Latin America (pp. 72-96). Bloomington, Indianoapolis: Indiana University Press.

Guber, R. (2011). La observación participante como sistema de contextualización de los métodos etnográficos. La investigación de campo de Esther Hermitte en los Altos de Chiapas, 1960-1961. Revista Latinoamericana de Metodología de las Ciencias Sociales, 1(2), 60-90.

Hernández, J. (1936). Prehistoria colombiana. Bogotá: Minerva.

Holmberg, A. (1954). Adventures in Culture Change. En Method and perspective in anthropology (pp. 103-113). Minneapolis: The University of Minnesota Press.

Jaramillo, J. (1996). Campesinos de los Andes: Estudio pionero en la Sociología colombiana. Revista Colombiana de Sociología, III(1), 53-82.

López de Mesa, L. (1930). Introducción a la historia de la cultura en Colombia. Bogotá: Sin más datos.

Machado, A. (2009). Ensayos para la historia de la política de tierras en Colombia. De la colonia a la creación del Frente Nacional. Bogotá: Universidad Nacional de Colombia. Facultad de Ciencias Económicas. Centro de Investigaciones para el Desarrollo (CID).

Ministerio de Agricultura (1959). Ministerio de Agricultura al Congreso Nacional. Convenio para llevar a cabo una política coordinada de fomento agropecuario por medio de la mecanización agrícola. Memoria del Ministerio de Agricultura al Congreso Nacional. Bogotá.

Ministerio de Agricultura, Caja de Crédito Agrario, Industrial y Minero, Departamento de Estudios Económicos y planeación financiera (1977a). Agremiaciones y corporaciones privadas e institucionales. Corporaciones financieras y autónomas. Bogotá: Ministerio de Agricultura, Caja de Crédito Agrario, Industrial y Minero, Departamento de Estudios Económicos y planeación financiera.

Ministerio de Agricultura, Caja de Crédito Agrario, Industrial y Minero, Departamento de Estudios Económicos y planeación financiera. (1977b). El sector agropecuario (síntesis). 1950-1975. Bogotá. Sin más datos.

Rojas, J. (2014a). Sobre la fundación de la sociología en Colombia. En Antología Orlando Fals Borda. Colección Obra Selecta (p. 386). Bogotá: Colección Obra Selecta.

Sánchez, W. (2014b). Los servicios de extensión rural en Colombia, una mirada desde la apropiación social de la ciencia y la tecnología. Universidad Nacional de Colombia. Bogotá: Facultad de Ciencias Humanas. Departamento de Sociología.

Shapin, S. (1988). The House of Experiment in Seventeenth-Century England, 79(3), 373-404.

Shapin, S. \& Schaffer, S. (2005). Leviathan and the air pump. Hobbes, Boyle and the experimental life. Buenos Aires: Universidad Nacional de Quilmes.

Shumacher, E. (1983a). Lo pequeño es hermoso. Barcelona: Ediciones Orbis.

Smith, T. (1958c). La Sociología Rural en los Estados Unidos de América y en Canadá. Revista Mexicana de Sociología, 20(3), 817-842.

Smith, T. Lynn. (1960). Apéndice para América Latina. En Sociología de la vida rural (Tercera edición, p. 646). Buenos Aires: Editorial Bibliográfica Argentina. 
Smith, L. (1980). The cohesiveness of Social Systems: A Factor in Resistance to Social Change. Adaptación. En A legacy of knowkedge. sociological contributions of T Lynn Smith (pp. 274-5). New Delhi: Vikas publishing house pvt ltd.

Solano, A. (15 de noviembre de 1953). La Melancolía de la Raza Indígena. El Tiempo. Bogotá.

Triana, M. (1951). La civilización chibcha (Quinta edición). Bogotá: Ministerio de Educación Nacional.

Trigo, E., Piñeiro, M. y Sábato, J. (1983b). La cuestión tecnológica y la organización de la investigación agropecuaria en América Latina. Desarrollo Económico, 23(89), 99-119.

Wynne, B. (2004). ¿Pueden las ovejas pastar seguras? Una mirada reflexiva sobre la separación entre conocimiento experto-conocimiento lego. Revista Colombiana de Sociología, 23, 109-157.

\section{Archivos Consultados}

-Archivo Documental Orlando Fals Borda ubicado en el Archivo de Investigadores del Archivo Histórico de la Universidad Nacional de Colombia.

-Archivo Satélite de Ciencias Humanas. Universidad Nacional de Colombia.

-Biblioteca del Ministerio de Agricultura

\section{Entrevistados}

-Don Julio Garzón

-Don Carlos Julio Sánchez

-Don Francisco Torres Quintero

-Doña Hilda Sánchez 